\title{
Failure Modeling of Titanium-61-4V and 2024-T3 Aluminum with the Johnson-Cook Material Model
}

G. Kay

September 16, 2002

U.S. Department of Energy

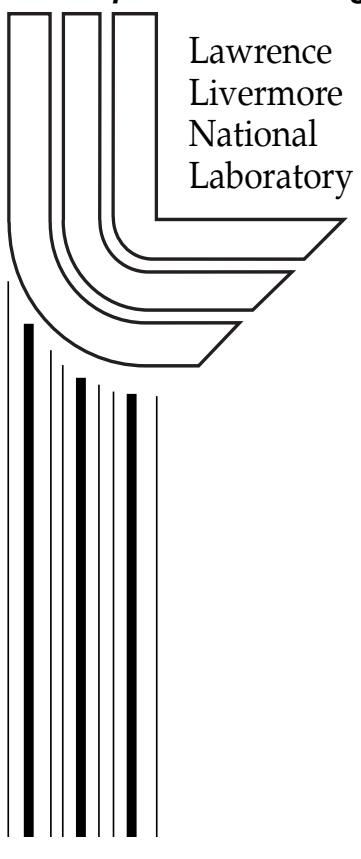




\section{DISCLAIMER}

This document was prepared as an account of work sponsored by an agency of the United States Government. Neither the United States Government nor the University of California nor any of their employees, makes any warranty, express or implied, or assumes any legal liability or responsibility for the accuracy, completeness, or usefulness of any information, apparatus, product, or process disclosed, or represents that its use would not infringe privately owned rights. Reference herein to any specific commercial product, process, or service by trade name, trademark, manufacturer, or otherwise, does not necessarily constitute or imply its endorsement, recommendation, or favoring by the United States Government or the University of California. The views and opinions of authors expressed herein do not necessarily state or reflect those of the United States Government or the University of California, and shall not be used for advertising or product endorsement purposes.

This work was performed under the auspices of the U. S. Department of Energy by the University of California, Lawrence Livermore National Laboratory under Contract No. W-7405-Eng-48.

This report has been reproduced directly from the best available copy.

Available electronically at http://www.doc.gov/bridge

Available for a processing fee to U.S. Department of Energy

And its contractors in paper from

U.S. Department of Energy

Office of Scientific and Technical Information

P.O. Box 62

Oak Ridge, TN 37831-0062

Telephone: (865) 576-8401

Facsimile: (865) 576-5728

E-mail: reports@adonis.osti.gov

Available for the sale to the public from

U.S. Department of Commerce

National Technical Information Service

5285 Port Royal Road

Springfield, VA 22161

Telephone: (800) 553-6847

Facsimile: (703) 605-6900

E-mail: orders@ntis.fedworld.gov

Online ordering: http://www.ntis.gov/ordering.htm

\section{OR}

Lawrence Livermore National Laboratory

Technical Information Department's Digital Library

http://www.llnl.gov/tid/Library.html 
Failure Modeling of Titanium-6Al-4V and 2024-T3 Aluminum with the Johnson-Cook Material Model

September 16, 2002

Final Report 


\section{TABLE OF CONTENTS}

Page

EXECUTIVE SUMMARY

1. INTRODUCTION 6

$\begin{array}{llr}1.1 & \text { Purpose } & 6\end{array}$

$\begin{array}{lll}1.2 & \text { Johnson-Cook material model } & 6\end{array}$

$\begin{array}{lll}1.3 & \text { Johnson-Cook failure model } & 7\end{array}$

2. FAILURE STRAIN PARAMETERS FOR TITANIUM 6AL-4V 8

2.1 Titatium 6Al-4V failure parameter determination 8

2.2 Scaled down ballistic limit tests $\quad 8$

2.3 Split Hopkinson bar tests 9

2.4 Ti-6Al-4V failure parameter validation 9

$\begin{array}{lll}2.5 & \text { Convergence issues } & 10\end{array}$

3. ALUMINUM 2024-T3 FAILURE STRAIN PARAMETERS 11

3.1 2024-T3 failure parameter determination 11

3.2 2024-T3 failure parameter validation 11

4. SUMMARY 13

5. ACKNOWLEDGMENTS 13

6. REFERENCES 14 


\section{LIST OF TABLES}

Table Page

1 Solution convergence issues were simplified after maintaining close-to 10 uniform mesh resolution for the titanium $6 \mathrm{Al}-4 \mathrm{~V}$ simulations

2 Solution convergence issues were simplified after maintaining close-to

12 uniform mesh resolution for the 2024-T3 aluminum simulations 


\section{LIST OF FIGURES}

$\begin{array}{ll}\text { Figure } & \text { Page }\end{array}$

1 Stress-strain results for the 0.025 " notch radius Ti-6Al-4V tensile 15 Hopkinson bar test specimen.

2 Stress-strain results for the 0.050 " notch radius Ti-6Al-4V tensile Hopkinson bar test specimen.

3 Johnson-Cook 6Al-4V titanium flow surfaces for varying strain rates $\left(\right.$ milli- $\left.-\mathrm{sec}^{-1}\right)$.

4 Johnson-Cook 6Al-4V failure strain for varying $\sigma^{*}$.

5 Calculated stress comparisons for the 0.025 " notch radius Ti-6Al-4V tensile Hopkinson bar test specimen.

6 Calculated stress comparisons for the 0.050 " notch radius Ti-6Al-4V tensile Hopkinson bar test specimen.

$7 \quad$ Crack pattern produced by the Johnson-Cook model and the observed pattern for Pratt \& Whitney titanium blade impact Test 5 .

8 Crack pattern produced by the Johnson-Cook model and the observed pattern for Pratt \& Whitney titanium blade impact Test 3.

$9 \quad$ NAWC China Lake Titanium panel Impact Test 16.

10 2024-T3 ballistic limit simulation comparisons with LLNL experimental results.

11 Johnson-Cook 2024-T3 flow surfaces for varying strain rates (milli-sec $\left.{ }^{-1}\right) . \quad 22$

12 Johnson-Cook 6Al-4V failure strain for varying $\sigma^{*}$. 23

13 NAWC engine debris test 17: Fan blade fragment impact with 23 a skin section.

14 NAWC engine debris test 22: Fan blade fragment impact with a skin/hat section.

15 NAWC engine debris test 14: Fan blade fragment impact with a skin/rib section. 


\section{Executive Summary}

A validated Johnson-Cook model could be employed to perform simulations relating to the containment aspects of aircraft and engine designs. This report describes the determination and validation of parameters that can be used to predict failure in Ti-6Al4V and 2024-T3 aluminum. The titanium parameters in this study were obtained from manually optimized simulations of Split- Hopkinson bar tensile tests. The aluminum failure parameters were obtained from optimized simulations of one-third scale ballistic limit test results. The failure parameters for both materials were validated on full scale penetration tests.

Ti-6Al-4V failure parameters that were derived from scaled down ballistic limit testing produced a failure envelope which was not suitable for use on full scale tests. The Ti6Al-4V parameters derived from scaled down tests were also not consistent with those determined by Hopkinson bar tests. Failure mode identification, material processing and rate effects are possible causes for this inconsistency and it is recommended that further investigation be initiated to assure validation for the ongoing FAA Aircraft Catastrophic Failure Prevention Program. 


\section{INTRODUCTION}

\subsection{Purpose}

A validated Johnson-Cook model could be employed to perform simulations that conform to FAA standards for evaluating aircraft and engine designs for airworthiness and containment considerations. A previous LLNL report [1] described the motivation for using the Johnson-Cook material model in simulations involving engine containment and the effect of uncontained engine debris on aircraft structures. In that report, experimental studies of the deformation and failure behavior of Ti-6Al-4V and 2024-T3 aluminum at high strain rates and large strains were conducted. The report also describes the generation of material constants for the Johnson-Cook strength model. This report describes the determination and validation of parameters for Ti-6Al-4V and 2024-T3 aluminum that can be used in the failure portion of the Johnson-Cook material.

\subsection{Johnson-Cook Material Model}

The Johnson-Cook flow surface is:

$$
\sigma_{\text {yield }}=\left[A+B\left(\bar{\varepsilon}^{p}\right)^{n}\right]\left[1+C \ln \left(\dot{\varepsilon}^{*}\right)\right]\left[1+\left(T^{*}\right)^{m}\right]
$$

where the non-dimensional temperature $T^{*}$ is given by $T^{*}=\frac{T-T_{\text {room }}}{T_{\text {melt }}-T_{\text {room }}}$. Adiabatic conditions are assumed such that all internal plastic work is converted into temperature change, i.e., $\Delta T=\frac{\overline{\sigma \varepsilon}^{p}}{\rho C_{v}}$, where $\bar{\sigma}$ is the effective stress, $\bar{\varepsilon}^{p}$ is the effective plastic strain, $\rho$ is the mass density and $C_{v}$ is the constant volume specific heat.The effective plastic strain $\bar{\varepsilon}^{p}$ is defined by $\bar{\varepsilon}^{p}=\int_{0}^{t} d \bar{\varepsilon}^{p}$, where the incremental plastic strain $d \bar{\varepsilon}^{p}$, is determined from the incremental plastic strain tensor $d \varepsilon_{i j}$, such that $d \bar{\varepsilon}^{p}=\sqrt{\frac{2}{3} d \varepsilon_{i j} d \varepsilon_{i j}}$. The effective stress $\bar{\sigma}$ is defined by $\bar{\sigma}=\sqrt{\frac{3}{2} \sigma_{i j} \sigma_{i j}}$. The non- dimensional strain rate $\dot{\varepsilon}^{*}$ is the ratio of the effective plastic strain rate $\vec{\varepsilon}^{p}$ to the reference strain rate $\dot{\varepsilon}^{0}$ (usually equal to 1.0), i.e., $\dot{\varepsilon}^{*}=\frac{\vec{\varepsilon}^{p}}{\dot{\varepsilon}^{0}}$. 


\subsection{Johnson-Cook failure model}

Failure accumulation in the Johnson-Cook model does not directly degrade the yield surface. The model, more fully described in [2], defines the strain at fracture as:

$$
\varepsilon_{\text {failure }}=\left[D_{1}+D_{2} \exp \left(D_{3} \sigma^{*}\right)\right]\left[1+D_{4} \ln \left(\dot{\varepsilon}^{*}\right)\right]\left[1+D_{5} T^{*}\right]
$$

where $\sigma^{*}$ is the ratio of the pressure to the effective stress, i.e., $\sigma^{*}=\frac{\text { pressure }}{\bar{\sigma}}$.

Fracture occurs in the Johnson-Cook model when the damage parameter $\mathbf{D}$ exceeds 1.0. The evolution of $\mathbf{D}$ is given by the accumulated incremental effective plastic strains divided by the current strain at fracture

$$
D=\sum \frac{\Delta \bar{\varepsilon}^{p}}{\varepsilon_{\text {failure }}}
$$

During the calculation, element stresses are all set to zero and remain equal to zero when the fracture criteria is evoked for a specific element.

The first set of brackets in the Johnson-Cook fracture model are intended to represent the observation that the strain to fracture decreases as the hydrostatic tension increases [3]. The second set of brackets in the strain to failure expression represent the effect of an increased strain rate on the material ductility, while the third set of brackets represent the effect of thermal softening on the material ductility. Johnson-Cook failure parameters for the two materials in this study have previously been published [4], but they were determined in conjunction with strength model parameters which are different from those employed in this study [1].

Failure strain dependency on the state of hydrostatic tension was considered in this study, i.e., $\varepsilon_{\text {failure }}=\left[D_{1}+D_{2} \exp \left(D_{3} \sigma^{*}\right)\right] D^{*}$, where $D^{*}$ is a constant. Failure strain parameters that are concerned with the strain rate and temperature, $D_{4}$ and $D_{5}$, were drawn from [4] in this study. The consequence of this restriction, imposed by the scope of the study, was diminished by the observation that the tests used to determine $D_{1}, D_{2}$ and $D_{3}$ were conducted at strain rates approximately equal to those encountered in the full scale tests. The $D_{1}, D_{2}$ and $D_{3}$ failure parameters were determined for each material by careful parameter adjustment until a manually optimized correlation was obtained with the appropriate split Hopkinson bar and ballistic limit tests. Several attempts were made to employ an optimizer code to accomplish the parameter determination but they ultimately did not prove as useful as the manual optimization. The primary difficulty that was encountered in the optimizer code application was the definition of a viable metric (for both the ballistic limit and the Hopkinson bar simulations) that was sensitive to reasonable parameter space variations. 


\subsection{FAILURE STRAIN PARAMETERS FOR TITANIUM 6AL-4V}

\subsection{Titanium 6Al-4V failure parameter determination}

The titanium-6Al-4V failure strain parameters for the Johnson-Cook failure model were determined by simulating the results of tensile Hopkinson bar tests employing 0.312 “diameter specimen geometries and notch radii of either 0.025 " or 0.050 ". The different notch radii provided a multi-axial loading range, as defined by $\sigma^{*}$, similar to that expected in the full scale penetration verification tests. The calculated stress and strain across the notch was compared to the measured stress and strain for a complete set of failure strain parameters $\left(D_{1}-D_{3}\right)$. These failure strain parameter sets were then varied until a statisfactory fit to the data was obtained. The parameters that were obtained from the Hopkinson bar tests were validated on two Pratt \& Whitney blade fragment tests with 0.601" and 0.737" thick targets and a Naval Air Warfare Center, China Lake blade fragment test on a 0.250 " thick titanium target.

\subsection{Scaled down ballistic limit tests}

Initially, Ti-6Al-4V failure parameters were derived from ballistic limit test data of fixed 6 " by 6" by 0.250 " thick targets that were impacted by 0.58 " diameter by 8.7 " long right circular cylinders [5]. These initial failure parameters produced a failure envelope that was not suitable for the simulation of the full scale penetration tests that were performed by Pratt \& Whitney [6] and the Naval Air Warfare Center, China Lake [7], i.e., the parameters predicted material responses that were much tougher than reality. This inconsistency could be attributed to the prediction of plugging or shear localization target failure with parameters that are based primarily on a material undergoing petaling (tearing) failure. The targets under consideration in this report can be classified [8] as being intermediate (the rear surface exerts influence on the penetration process) to thick (influence of the boundary is felt only after substantial target penetration). For these targets, a pronounced change in slope has been reported [9] when the ballistic limit velocity is plotted against the target areal weight (mass density times thickness). This change in slope, attributed to a change in target failure mode from petaling to plugging, tends to flatten out the response curve, producing a decreasing change in ballistic limit with increasing target areal density. Thus, “...it appears that a smaller percentage of the projectile's kinetic energy at impact is transferred to the plate when the plate undergoes a shear (plug) mode failure than when it undergoes a petal (tear) mode failure. This implies that projectile limit speed could be lower for a shear failure than for a petal failure all else held constant (i.e., if the plate had a choice of failure mode)" [5]. The inconsistency from using scaled down ballistic limit data on full size events could be also be due to material processing or loading rates. This situation merits further investigation into the condition of the material and the ability of the model to distinguish between failure modes. The initial Ti-6Al-4V failure parameters were also not consistent with the parameters determined later by the tensile Hopkinson bar tests. 


\subsection{Split Hopkinson bar tests}

Stress and strain data were collected at two specimen locations in the Hopkinson bar tensile tests. Specimen stress time histories were inferred from strain gauge data that was recorded on a transmitter bar that was attached to the tensile specimen. Strain time histories were inferred from optical results of a framing camera looking at notch elongations during the passage of the tensile waves. These two signals were cross plotted, after adjusting for the time delays due to the separation of the data recording locations. This somewhat subjective procedure was duplicated in the simulations, where elongation was measured and compared to the original notch gauge length for strain, and the strain at the transmitter bar was converted to stress to infer uniaxial stress conditions in the specimen. The $2 \mathrm{~d}$ mesh that was employed in these simulations is shown in Figure 1 as are the stress and strain comparisons with the data for the small radius specimens. The stress and strain comparisons for the large notch case are shown in Figure 2. The small radius specimen had a notch radius of 0.25 " and a nominal diameter of 0.100 ", and the large radius specimen had a notch radius of 0.500 " and a nominal diameter of 0.100 ". Failure parameters were developed that bounded the results for both notch cases, i.e., $+5.9 \%$ error for the small notch and $-5.8 \%$ error for the large notch. The failure parameters that were obtained by the Hopkinson bar test simulations are given in Figure 4. The flow surface, from [1], that was used in the simulations is shown in Figure 3.

The assumption of a dynamic homogeneous response may be reasonable for small uniform specimens (prior to necking) in split Hopkinson bar tests, but the existence of a notch certainly raises issues about a similar assumption for the above tests. The change in effective stress across the notches in the above tests can be seen in Figures 5 and 6, as well as the average stresses calculated for the transmitter bar. As can be seen, the calculated effective stresses across the notches are fairly uniform, but they do differ from the transmitter bar stresses (which are used in the experimental results). This difference was considered intrinsic to the use of a Hopkinson bar test using notched specimens. Local and average strain rates also differ, the maximum extensional strain rates as measured during the tests were $6,800 \mathrm{sec}^{-1}$ and $4,300 \mathrm{sec}^{-1}$ for the small and large radii specimens respectively, while the maximum calculated local strains rates for the same specimens were 13,500 $\mathrm{sec}^{-1}$ and 10,700 $\mathrm{sec}^{-1}$.

\subsection{Ti-6Al-4V failure parameter validation}

The failure strain parameters obtained from the tensile Hopkinson bar tests were validated on penetration tests performed by Pratt \& Whitney [6] and the Naval Air Warfare Center, China Lake[7]. The Pratt \& Whitney test targets were rolled plate Ti$6 \mathrm{Al}-4 \mathrm{~V}$ with a specification of AMS4911 in thicknesses of 0.601 " and 0.737 ". The targets were in a free boundary condition, hanging from holes in the corner of each 36 inch square flat plate. The projectiles were approximately $8 \mathrm{lbs}$ and were "beveled at the nose to simulate a fan blade root impact footprint". Available test data consisted of the initial conditions plus photographs and observations of the post test target condition. Simulation results are shown in Figures 7 and 8 for tests 3 and 5. In both cases, the 
simulation predicted the correct amount of penetration, and approximate crack patterns, which were characterized by P\&W as being "under-contained". The NAWC China Lake tests included the impact of an actual titanium fan blade fragment into a 0.250 " thick Ti6Al-4V panel which was supported along two opposing edges. The target material had a lower yield strength (135 ksi) than the Pratt \& Whitney and LLNL test materials (159 ksi). For the NAWC China Lake test simulation, the flow model was adjusted to account for the lower strength materials and is shown in Figure 9. The calculated residual velocity of $202 \mathrm{ft} . / \mathrm{sec}$ compares well with the measured residual velocity of $211 \mathrm{ft} . / \mathrm{sec}$ (a $-4.27 \%$ error). The actual and simulated final test panel deformation are also shown in Figure 9.

\subsection{Convergence issues}

Solution convergence issues were simplified in this study by maintaining close-to uniform mesh resolution for the Ti-6Al-4V simulations. The through-the-thickness mesh resolutions are shown in Table 1. An element aspect ratio less than 3.0 to 1.0 was maintained throughout this portion of the study. Eight node solid brick elements with a one-point integration were employed throughout this study. The outer regions of the targets were sometimes meshed with fewer elements through the thickness (by a factor of three) and then "tied" to the finer zoned impact region, to reduce the number of elements in each calculation. The finer zoned impact region extended to between two to three times the relevant impactor dimension.

Table 1: Solution convergence issues were simplified after maintaining close-to uniform mesh resolution for the Ti-6Al-4V simulations.

\begin{tabular}{|l|l|l|l|l|}
\hline Simulation & $\begin{array}{c}\text { Target } \\
\text { thickness } \\
\text { (inch) }\end{array}$ & $\begin{array}{c}\text { Thickness } \\
\text { resolution } \\
\text { (inch/ } \\
\text { element) }\end{array}$ & $\begin{array}{l}\text { Symmetry } \\
\text { conditions }\end{array}$ & Total elements \\
\hline $\begin{array}{l}\text { Split Hop } \\
\text { kinson bar } \\
\text { tests }\end{array}$ & 0.312 & .0167 & $\begin{array}{l}\text { 2D - axisy } \\
\text { metric model }\end{array}$ & 6021 \\
\hline P\&W test 3 & 0.601 & .0500 & $\begin{array}{l}3 \mathrm{D}-1 / 4 \\
\text { symmetry } \\
\text { model }\end{array}$ & 209,220 \\
\hline P\&W test 5 & 0.737 & .0491 & $\begin{array}{l}3 \mathrm{D}-1 / 4 \\
\text { symmetry } \\
\text { model }\end{array}$ & 110,400 \\
\hline $\begin{array}{l}\text { China Lake } \\
\text { test 16 }\end{array}$ & 0.250 & .0417 & $\begin{array}{l}3 \mathrm{D}-1 / 4 \\
\text { symmetry } \\
\text { model }\end{array}$ & 70,706 \\
\hline
\end{tabular}




\subsection{4-T3 ALUMINUM FAILURE STRAIN PARAMETERS}

\subsection{4-T3 failure parameter determination}

The 2024-T3 parameters for the Johnson-Cook failure strain model were determined by simulating the results of ballistic limit tests which were conducted by LLNL [5]. In those tests, a titanium "fragment simulant projectile" (FSP) impacted fixed boundary 0.150 " and 0.100" thick 6"X 6" 2024-T3 sheets. The FSP is a 0.050" diameter cylinder with a beveled nose. Recorded data included ballistic limit velocities and an estimation of the ballistic limit experimental variance.

The 2024-T3 ballistic limit was determined in the simulations by plotting the target fragment velocity against a range of initial projectile velocities for a complete set of failure strain parameters $\left(D_{1}-D_{3}\right)$. These failure strain parameter sets were then varied until a statisfactory fit to the data was obtained. The results of the simulation and the experimental results are shown in Figure 10 for the best-fit of the Johnson-Cook failure parameters. Calculated ballistic limits deviated from the measured values by $0.6 \%$ for the 0.100 " plate and $5.73 \%$ for the 0.150 " thick target. The failure parameters that were used in the ballistic limit simulation are given in Figure 12 and the revised flow surface which was used in the simulations is shown in Figure 10. Close to uniform mesh resolutions were maintained for the 2024-T3 simulations and they are shown in Table 2. An element aspect ratio less than 4.0 to 1.0 was maintained throughout this portion of the study and eight node solid brick elements with a one-point integration were also employed. All meshes were $3 \mathrm{D}$ in nature.

\subsection{4-T3 failure parameter validation}

The 2024-T3 failure strain parameters were validated on penetration tests performed by the Naval Air Warfare Center, China Lake [10]. In the NAWC China Lake tests, actual fragments from fan blades were launched into a B-727 fuselage. Impact velocity magnitudes and orientations were recorded as well as the residual projectile velocities. The fan blade fragments weighed approximately $0.7 \mathrm{lb}$. Test targets that were simulated included fuselage skin only, fuselage skin and a "hat-stringer", and fuselage skin plus an offset rib.

NAWC test 17, an impact between a blade fragment traveling $505 \mathrm{ft} . / \mathrm{sec}$ and a fuselage skin panel resulted, in a residual fragment velocity of $441 \mathrm{ft} . / \mathrm{sec}$. The calculated residual velocity of $451 \mathrm{ft} . / \mathrm{sec}$ is in error by $2.3 \%$. The test and simulated final deformations are shown in Figure 13. Shown in Figure 14 are the results of the simulation of NAWC test 22. This was a more complicated geometry, with an aluminum hat section that was riveted to the aluminum skin approximately every 1.25 " inches. The rivets were not included in the analysis and the hat section base was fully merged to the skin panel. The 
calculated residual velocity for test 22 was in error by $-1.2 \%$. NAWC shot 14 entailed the impact of a 0.694 pound blade fragment into a skin panel with an offset rib which was fixed to raised frame around the skin pane. The post shot configuration and simulation results are shown in Figure 15. The simulation error of $-14.1 \%$ is larger than the other two NAWC simulations and may be due to inaccuracies in the meshing of the rib section.

Table 1: Solution convergence issues were simplified after maintaining close-to uniform mesh resolution for the 2024-T3 aluminum simulations

\begin{tabular}{|c|c|c|c|c|}
\hline Simulation & $\begin{array}{c}\text { Target depth } \\
\text { (inch) }\end{array}$ & $\begin{array}{c}\text { Target depth } \\
\text { mesh } \\
\text { resolution } \\
\text { (inch/ } \\
\text { element) }\end{array}$ & $\begin{array}{c}\text { Symmetry } \\
\text { assumption }\end{array}$ & $\begin{array}{c}\text { Total number } \\
\text { of elements }\end{array}$ \\
\hline \hline LLNL ballistic limit & 0.100 & 0.0125 & $1 / 4$ & 9,936 \\
\hline LLNL ballistic limit & 0.150 & 0.0125 & $1 / 4$ & 14,304 \\
\hline NWAC shot 14 & 0.102 & 0.0170 & none & 51,940 \\
\hline NWAC shot 17 & 0.078 & 0.0125 & none & 33,388 \\
\hline NWAC shot 22 & 0.101 & 0.0163 & none & 53,276 \\
\hline
\end{tabular}




\subsection{SUMMARY}

Johnson-Cook failure strain parameters were developed for Ti-6Al-4V and 2024-T3 aluminum. Ti-6Al-4V parameters were verified on two LLNL tensile Hopkinson bar tests with 0.312 " diameter specimens and differing notch radii. The Ti-6Al-4V parameters were then successfully used to simulate Pratt\&Whitney full scale blade fragment tests on 0.602 "and 0.737 " thick targets and on a NAWC China Lake full size blade fragment test on a 0.250 " thick target. The failure mode for the validation tests was by plugging. Failure parameters for the 2024-T3 aluminum were determined from LLNL ballistic limit tests on 0.100 " and 0.150 " targets. These 2024-T3 aluminum failure parameters were used to simulate tests results on two blade fragment impact tests against a B-727 fuselage conducted by the NAWC, China Lake.

Ti-6Al-4V failure parameters that were derived from scaled down ballistic limit testing produced a failure envelope which was not suitable for use on full scale tests. Failure mode identification, material processing and rate effects are possible causes for this inconsistency, and it is recommended that they be further investigated to assure the validity of the ongoing FAA Aircraft Catastrophic Failure Prevention Program.

\section{ACKNOWLEDGMENTS}

This work was performed under the auspices of the U.S. Department of Energy by the Lawrence Livermore National Laboratory under contract No. W-7405-ENG-48. The author is indebted to Donald Lesuer and Mary LeBlanc for the split Hopkinson bar testing and to Ray Gogolewski and Bruce Morgan for the ballistic limit testing, all of which was performed at LLNL. Thanks also go to Steve Lundin at the Naval Air Warfare Center, China Lake for the fan blade/fuselage testing data and to D. G. Alexander and L. M. Dietz from Pratt \& Whitney for the blade/containment target data. Rich Couch was the program manager for FAA sponsored project at LLNL. 


\section{REFERENCES}

1. Donald Lesuer, 'Experimental Investigation of Material Models for T-6Al-4V and 2024-T3”, Lawrence Livermore National Laboratory, UCRL-xxxxx-xx, 1999.

2. Johnson, G.R. and Cook, W. H., "Fracture Characteristics of Three Metals Subjected to Various Strain, Strain Rates, Temperatures and Pressures", Engineering Fracture Mechanics, Vol. 21, No 1, pp. 31-48, 1985.

3. Hancock, J.W. and Mackenzie, A.C., "On the mechanism of ductile failure in highstrength steels subjected to multi-axial stress-states", J. Mech. Phys. Sol., pp. 147175,1976

4. Johnson, G.R. and Holmquist, T.J., "Test Data and Computational Strength and Fracture Model Constants for 23 Materials Subjected to Large Strains, High Strain Rates, and High Temperatures", Los Alamos National Laboratory, LA-11463-MS, 1989.

5. Gogolewski, R. P. and Morgan, B. R., "Fundamental Experiments in Penetration Mechanics”, Lawrence Livermore National Laboratory, UCRL-Xxxxx-Xx, 1999.

6. Alexander, D. G. and Dietz, L. M., Pratt \& Whitney memo FR-24864-8, October 12, 1999.

7. Steven J. Lundin, "Advanced Aircraft Materials Penetration Testing”, Naval Air Warfare Center, China Lake, Draft Report v6, 2002

8. Backman, M. E. and Goldsmith, W. Int. J. Eng. Sci., Vol 16, pp 1

9. Gogolewski, R. P. and Cunningham, B. J., "Terminal Ballistic Experiments for the Development of Turbine Engine Blade Containment Technology", Lawrence Livermore National Laboratory, UCRL-ID-120930, 1995

10. Steven J. Lundin, "Engine Debris Fuselage Penetration Testing Phase 1", Naval Air Warfare Center, China Lake, Draft Report, September 1999 


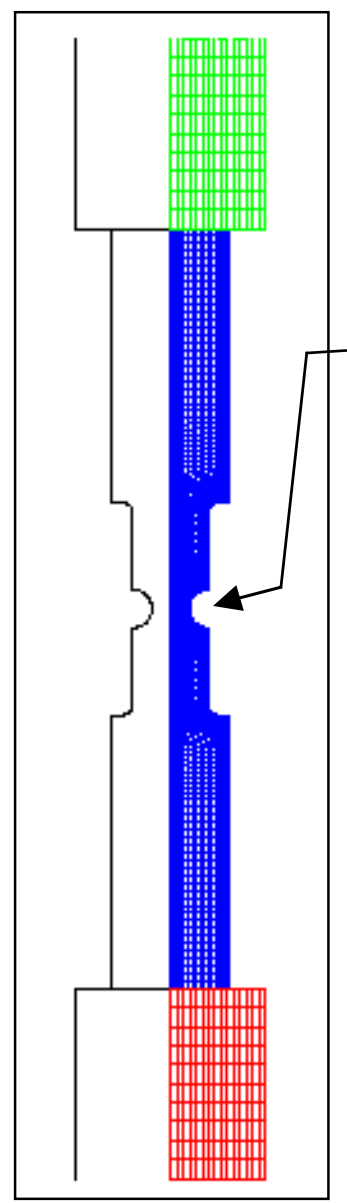

Measured extensional strain across the notch was 0.320 ", the calculated strain was $0.339 "$, a $5.9 \%$ error

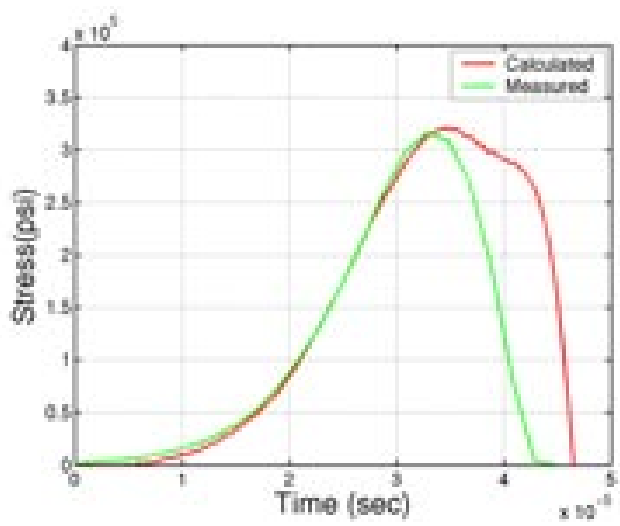

Stress time history of the transmitter bar strain gauge

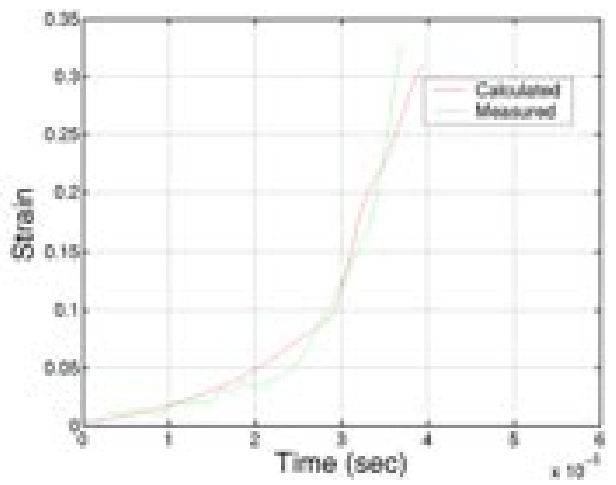

Strain time history across the notch

Figure 1. Stress-strain results for the 0.025 " notch radius Ti-6Al-4V tensile Hopkinson bar test 


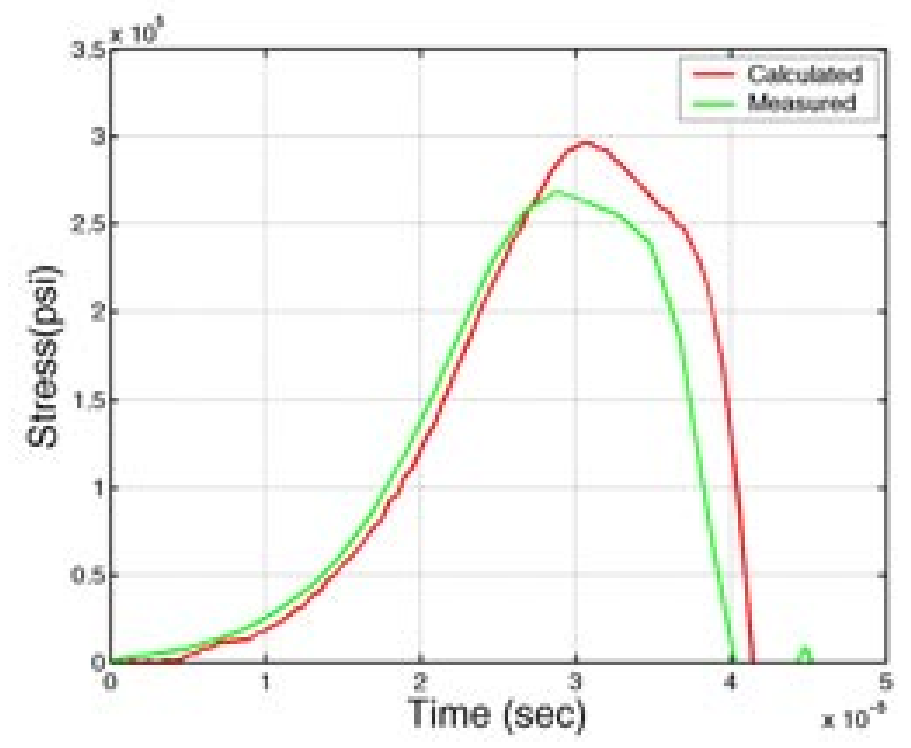

Stress time history of the transmitter bar strain gauge

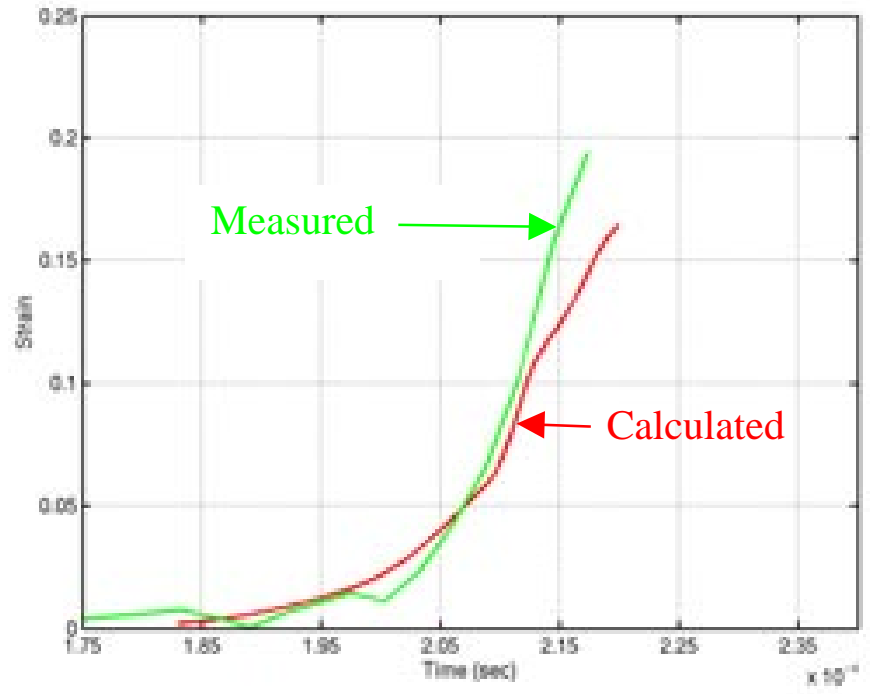

Strain time history across the notch

Figure 2. Stress-strain results for the 0.050 " notch radius Ti-6Al-4V tensile Hopkinson bar test 
Titanium 6Al-4V yield surface parameters [1]

$$
\begin{array}{ll}
A=159.246 \mathrm{ksi} & n=0.93 \\
B=158.376 \mathrm{ksi} & m=1.1 \\
C=0.014 &
\end{array}
$$

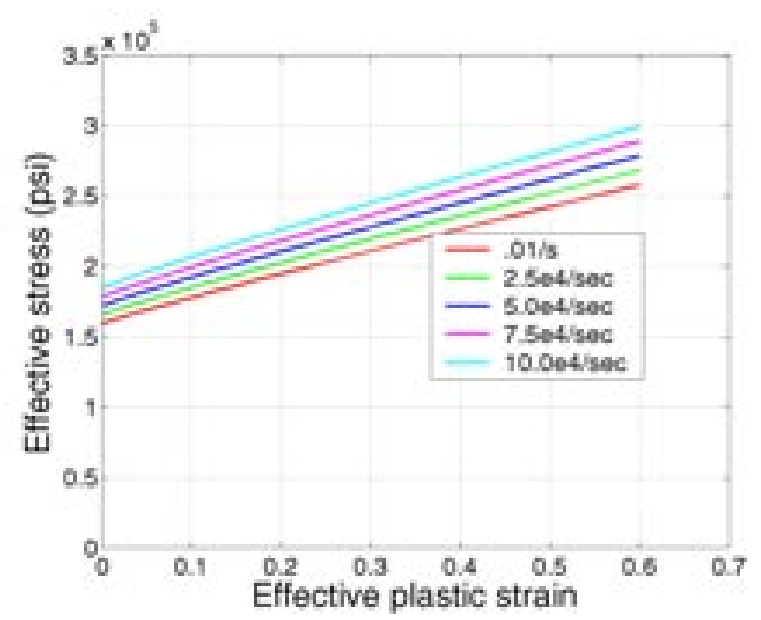

Figure 3. Johnson-Cook Ti-6Al-4V flow surfaces for varying strain rates

Titanium 6Al-4V failure strain parameters

$$
\begin{array}{ll}
D_{1}=-0.090 & D_{4}=0.014 \\
D_{2}=0.270 & D_{5}=3.870 \\
D_{3}=0.480 &
\end{array}
$$

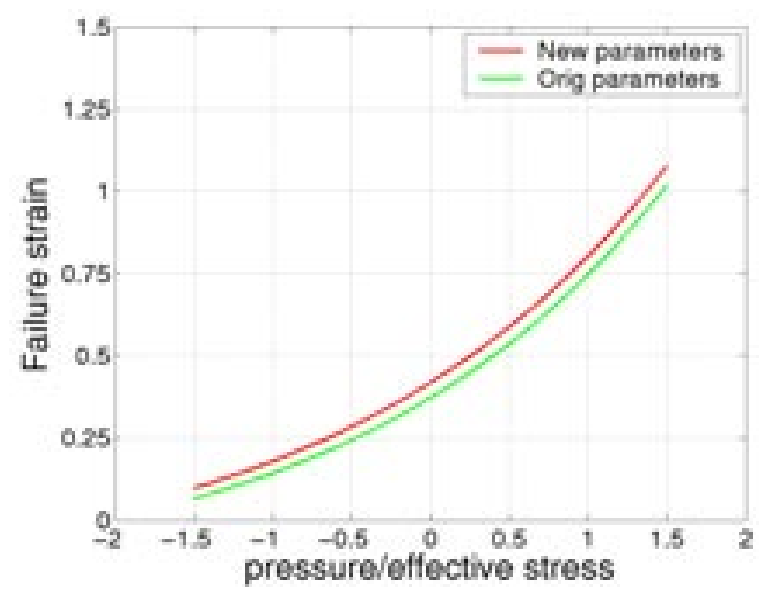

Figure 4. Johnson-Cook Ti-6Al-4V failure strains for varying $\sigma^{*}$ 


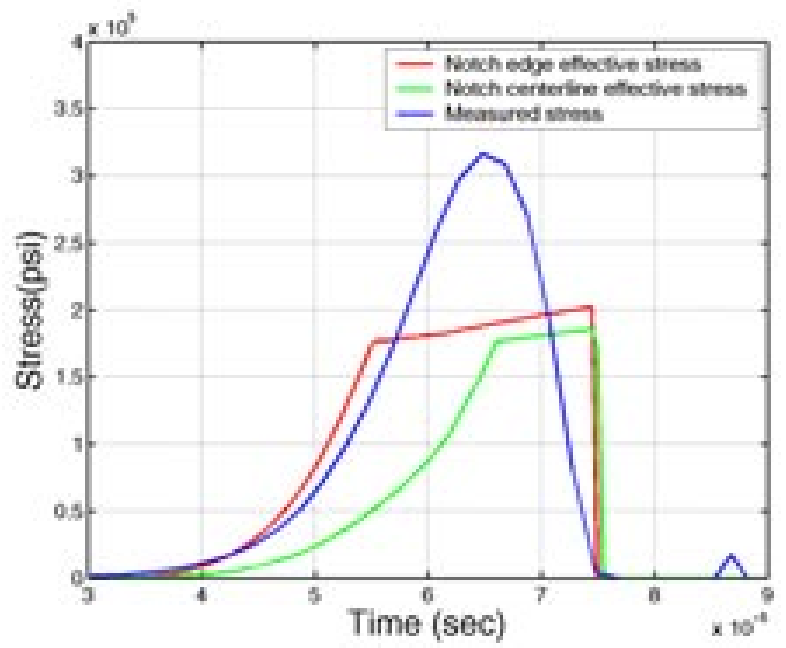

Figure 5. Calculated stress comparisons for the 0.025" notch radius Ti-6Al-4V Tensile Hopkinson bar test

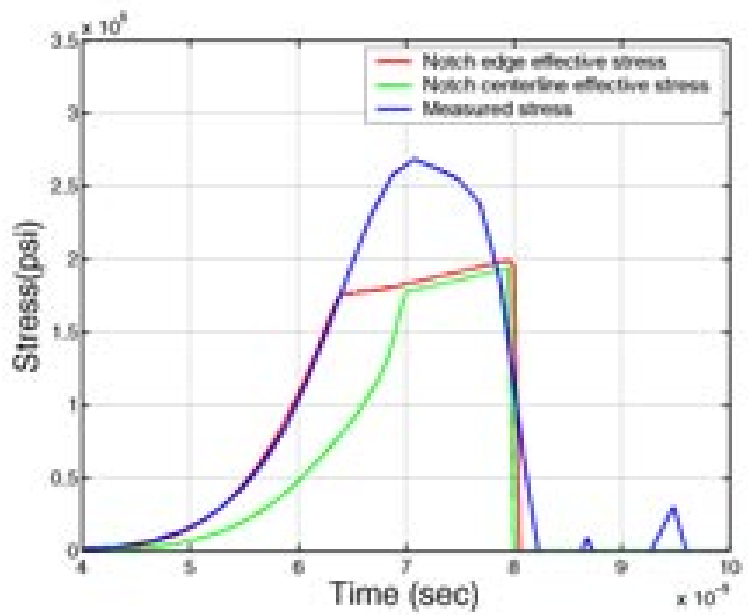

Figure 6. Calculated stress comparisons for the 0.050" notch radius Ti-6Al-4V Tensile Hopkinson bar test 


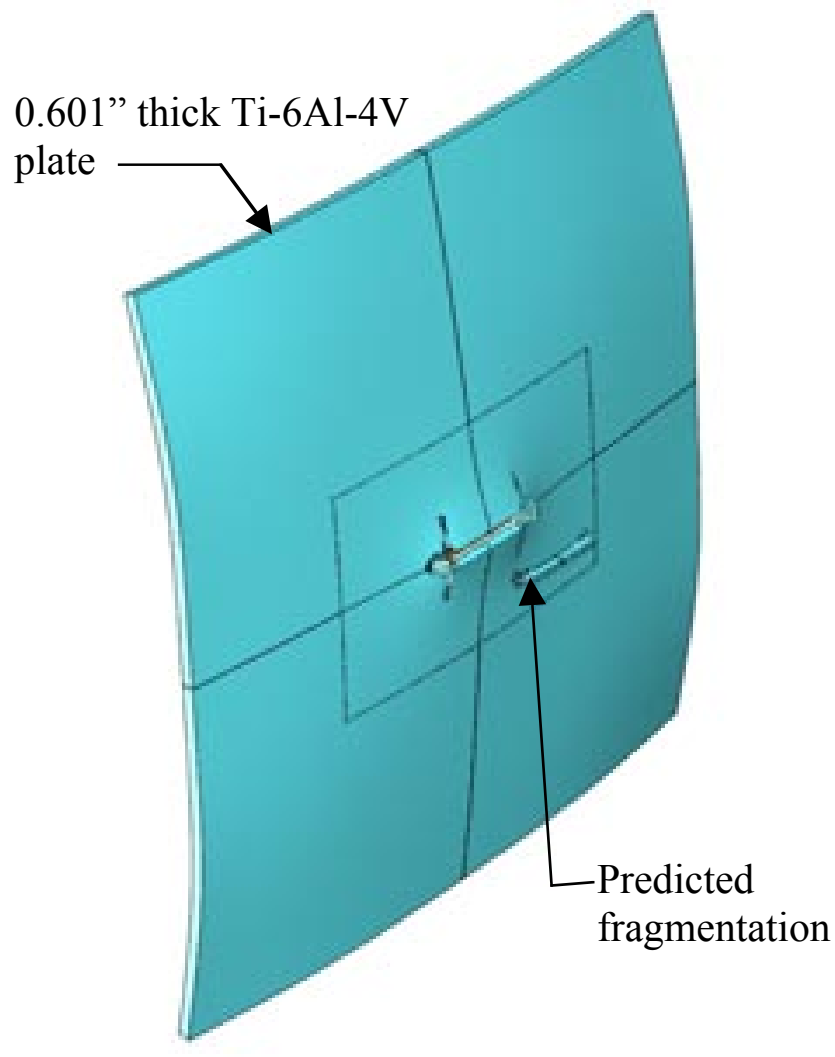

Initial velocity of the blade fragment was $547 \mathrm{ft} / \mathrm{sec}$

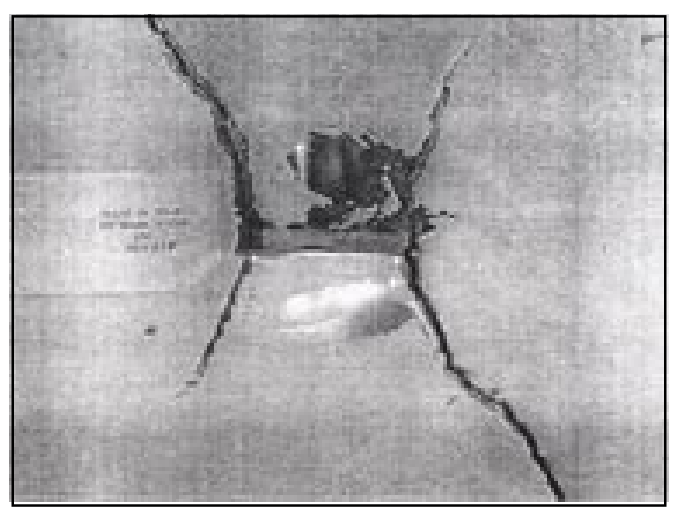

Rear view of Pratt \& Whitney Shot 5

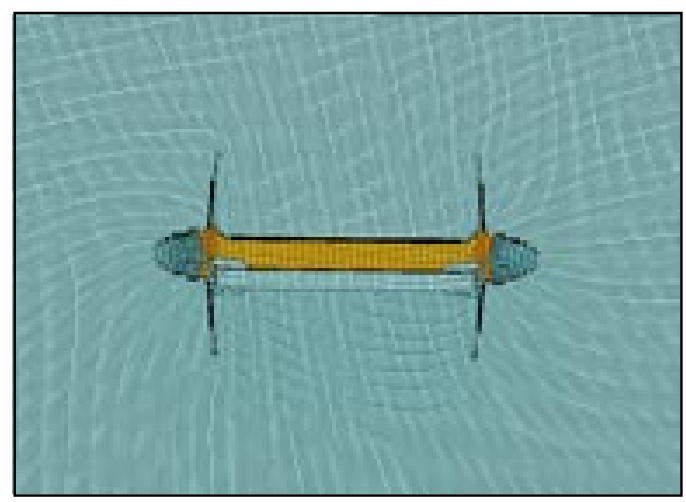

Johnson-Cook model prediction

Figure 7. Crack pattern produced by the Johnson-Cook model and the observed pattern for Pratt \& Whitney titanium blade impact Test 5. 
Initial velocity of the blade fragment Was $547 \mathrm{ft} / \mathrm{sec}$

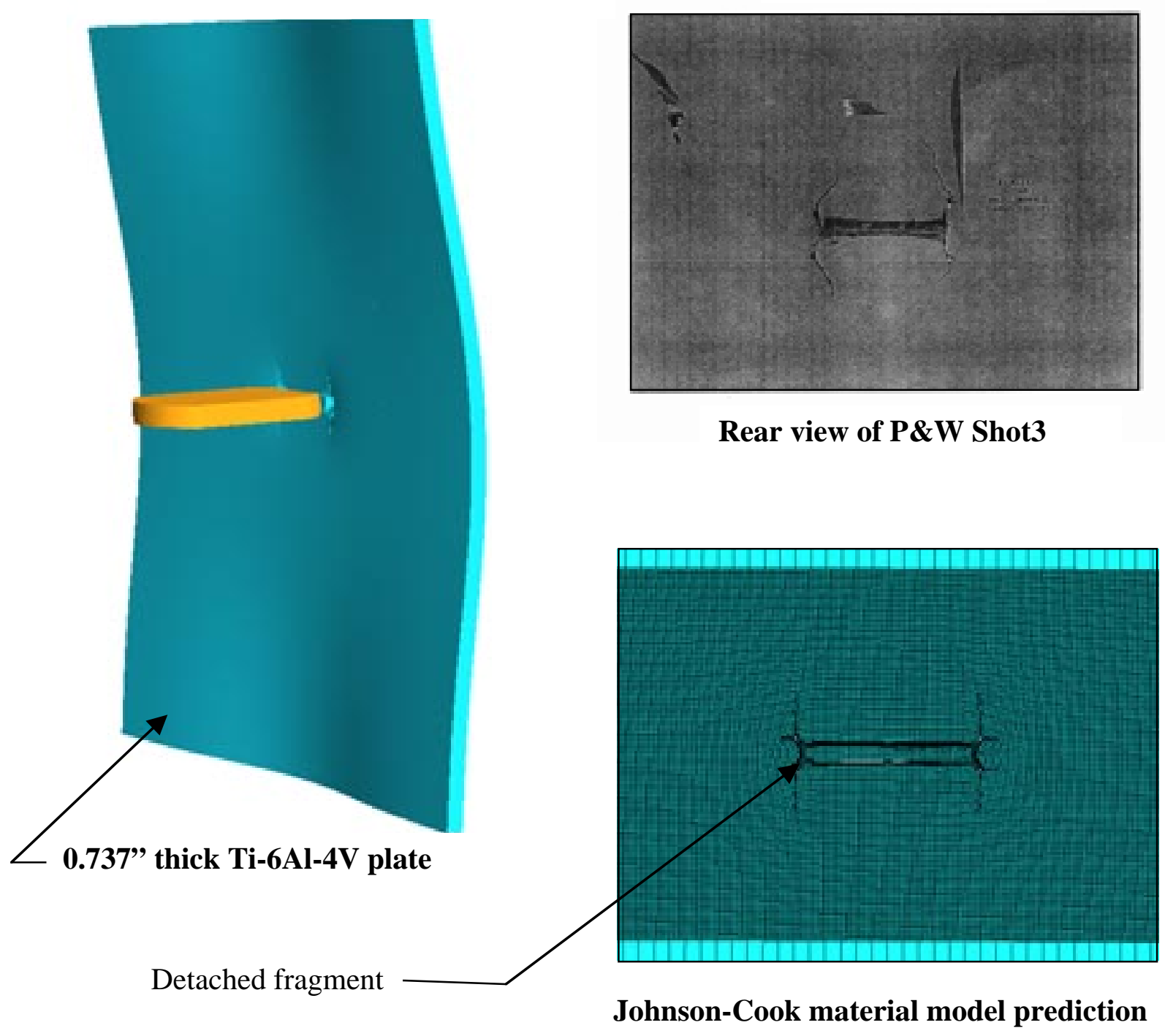

Figure 8. Crack pattern produced by the Johnson-Cook model and the observed Pattern for Pratt \& Whitney titanium blade impact Test 3. 


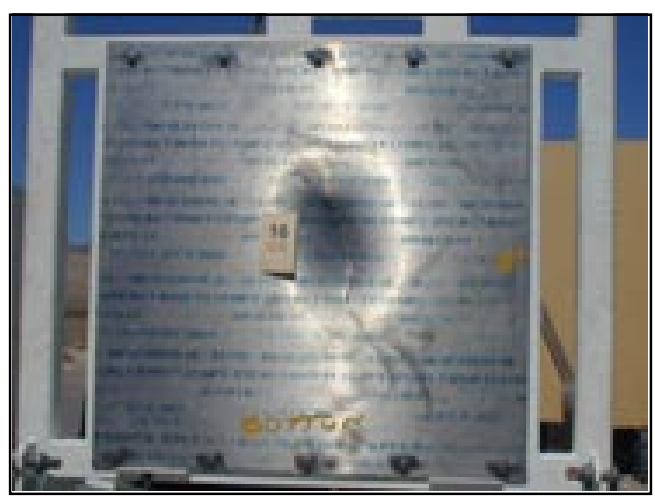

Measured residual velocity $=211 \mathrm{ft} / \mathrm{sec}$

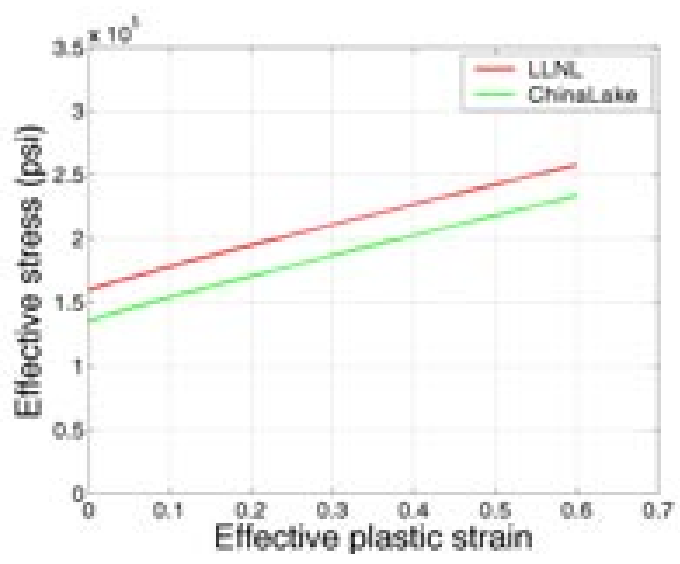

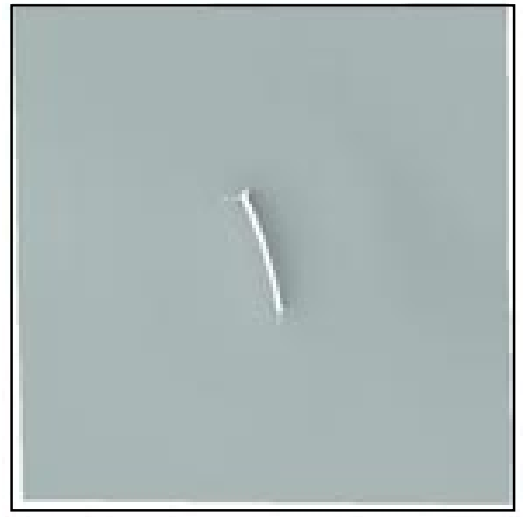

Calculated residual velocity $=202 \mathrm{ft} / \mathrm{sec}$, a $-4.27 \%$ error. The FEA mesh contained 83,743 nodes and 70,076 solid elements

The flow strength model was adjusted to reflect the difference between the China Lake titanium and the titanium that was tested at LLNL.

Figure 9. NAWC China Lake Titanium panel impact Test 16. 


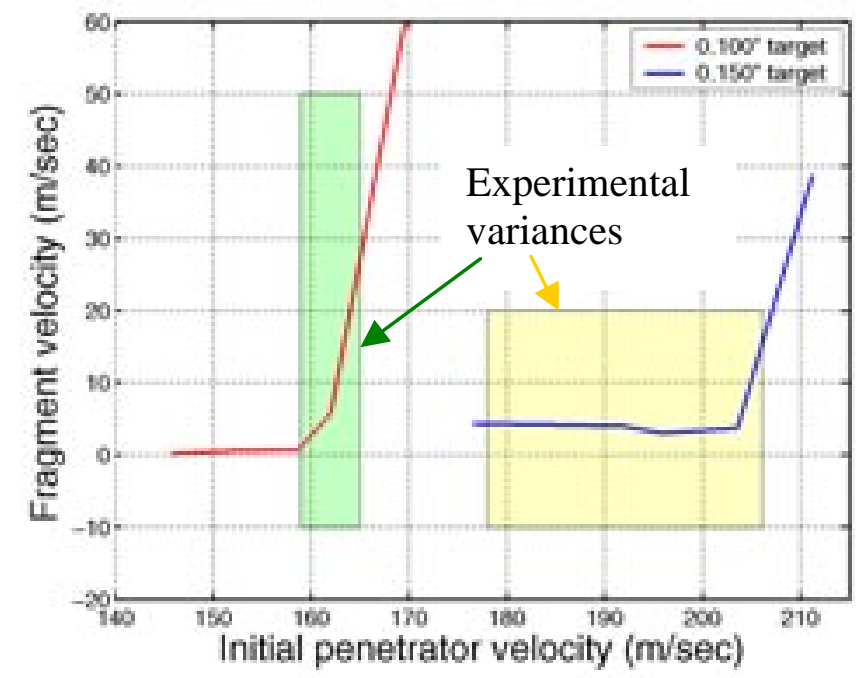

Figure 10. 2024-T3 ballistic limit simulation comparisons with LLNL experimental results

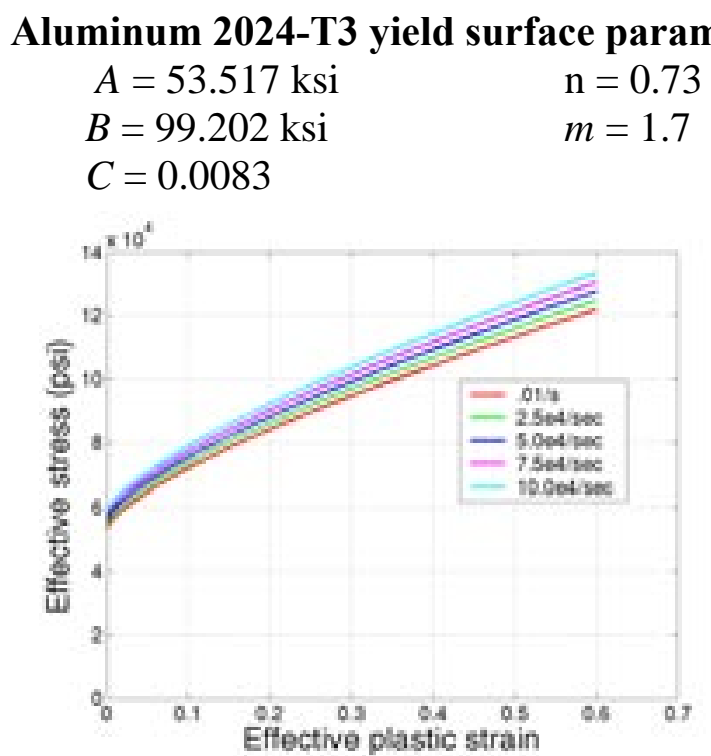

Figure 11. Johnson-Cook 2024-T3 flow surfaces for varying strain rates 
Aluminum 2024-T3 failure strain parameters

$$
\begin{array}{ll}
D_{1}=0.112 & D_{4}=0.007 \\
D_{2}=0.123 & D_{5}=0.0 \\
D_{3}=1.500 &
\end{array}
$$

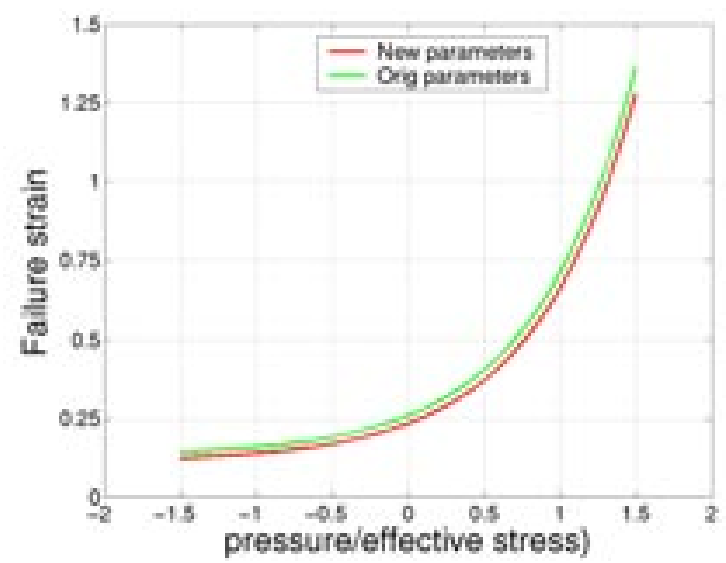

Figure 12. Johnson-Cook 2024-T3 aluminum failure strains for varying $\sigma^{*}$

Initial velocity of the blade fragment was $505 \mathrm{ft} / \mathrm{sec}$

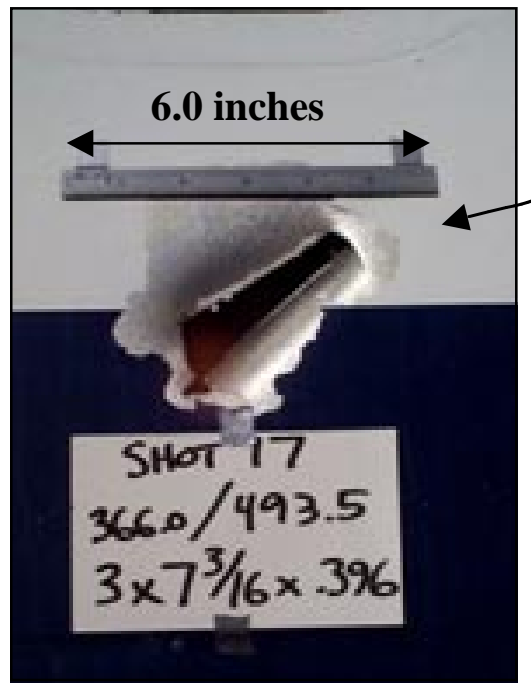

0.0875, average aluminum skin thickness

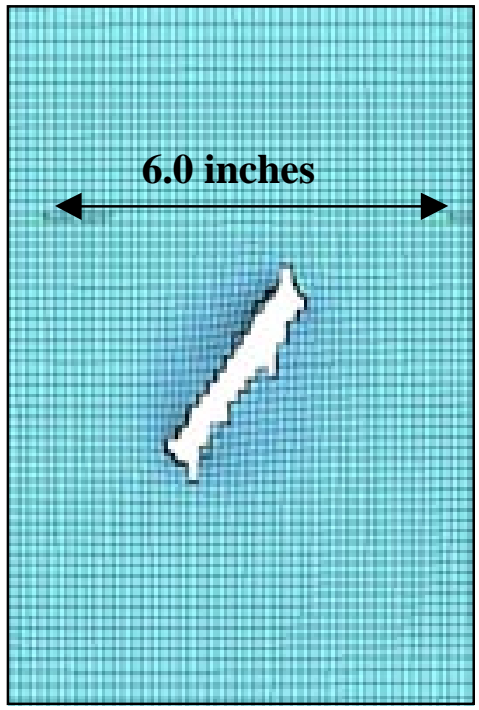

Measured residual velocity $=441 \mathrm{ft} / \mathrm{sec}$

Calculated residual velocity $=\mathbf{4 5 1} \mathrm{ft} / \mathrm{sec}$, a $2.3 \%$ error.

Figure 13. NAWC engine debris test 17: Fan blade fragment impact with a skin section 


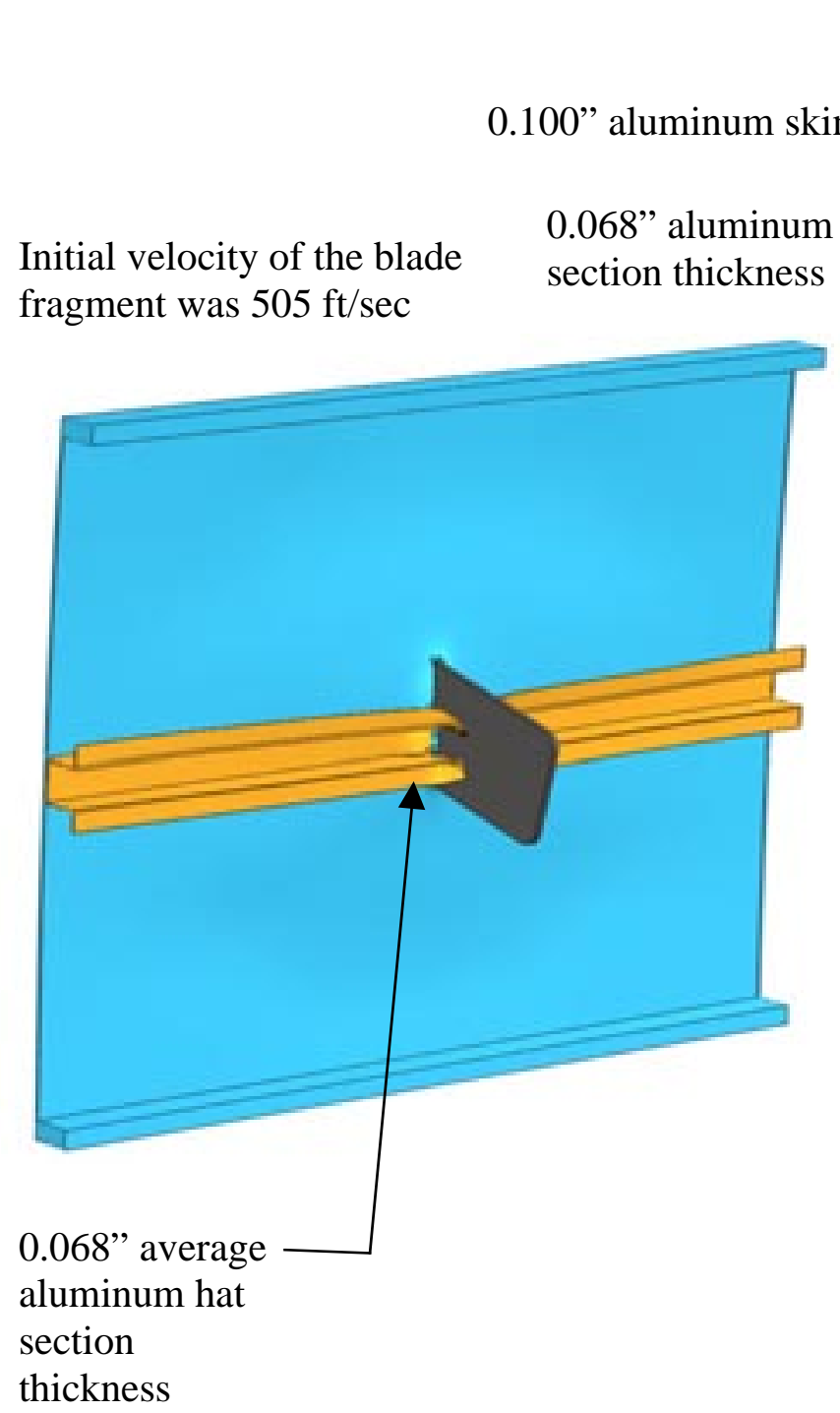

The mesh contained 122,625 nodes and 94,4200 solid brick elements. The hat section base was merged to the skin panel.

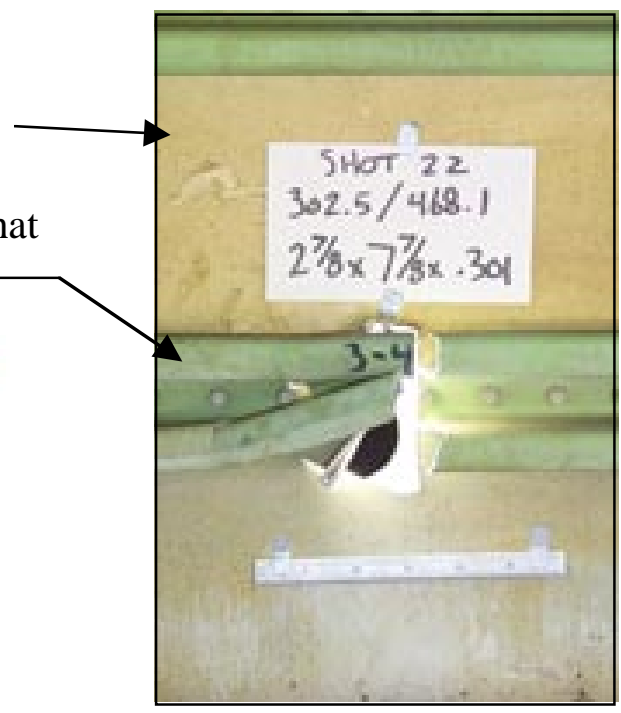

Measured fragment residual velocity $=725 \mathrm{ft} / \mathrm{sec}$

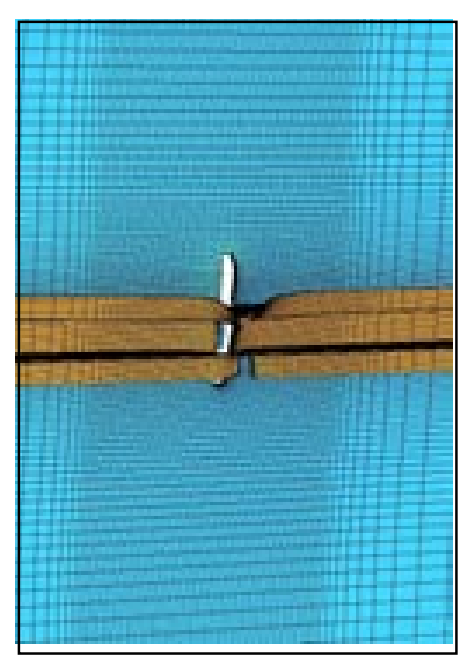

Calculated fragment residual velocity $=716 \mathrm{ft} / \mathrm{sec}$, a $1.2 \%$ error

Figure 14. NAWC engine debris test 22: Fan blade impact with a skin/hat section 
Initial velocity of the blade fragment was $802 \mathrm{ft} / \mathrm{sec}$
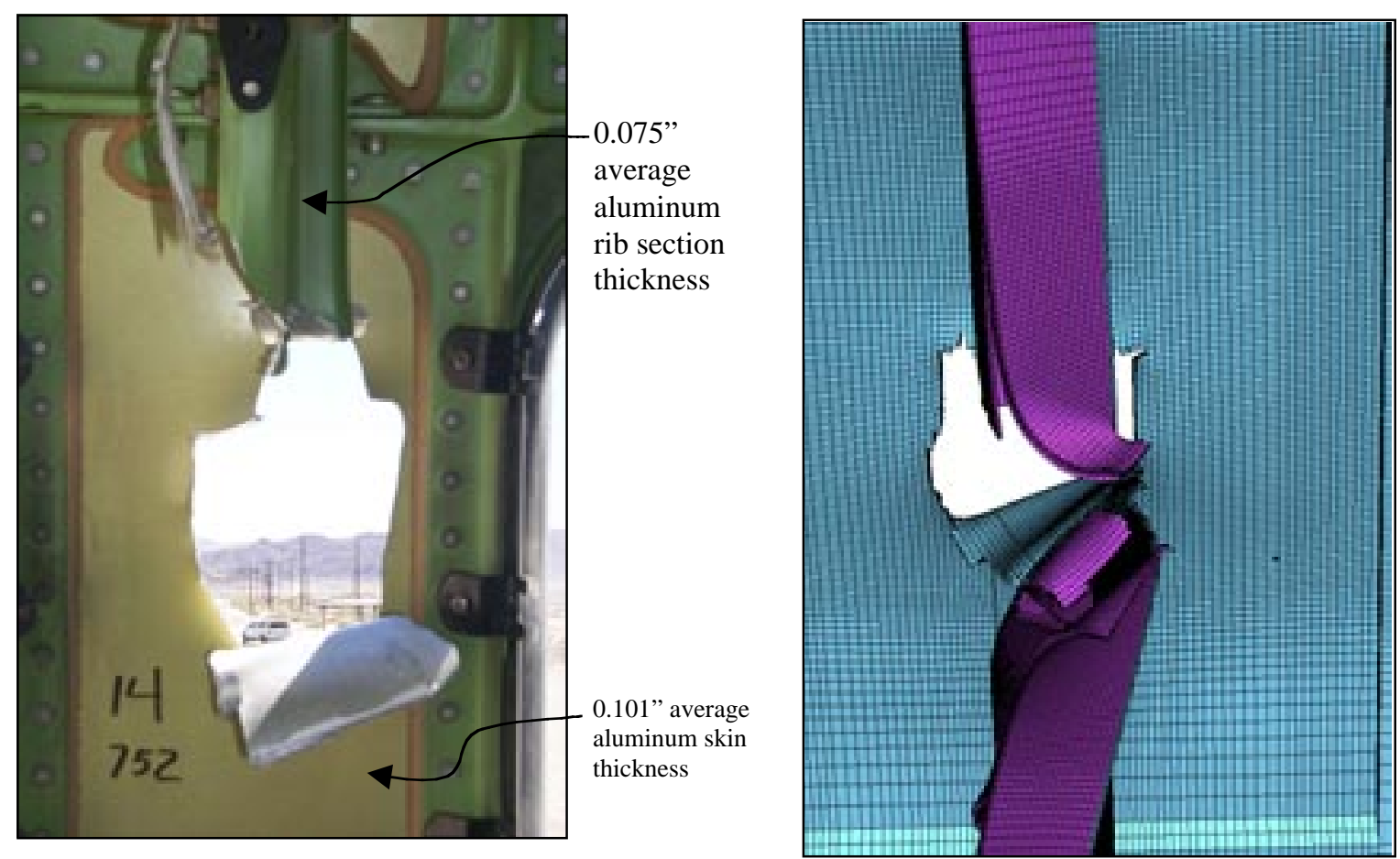

Measured residual velocity $=620 \mathrm{ft} / \mathrm{sec}$.

Calculated residual velocity $=\mathbf{5 3 3} \mathrm{ft} / \mathrm{sec}$, a $-\mathbf{1 4 . 0 \%}$ error.

Figure 15. NAWC engine debris test 14: Fan blade impact with a skin/rib section. 